\title{
Assessing the oral health literacy: A review
}

Oral health literacy is the degree to which individuals have the capacity to obtain, process and understand basic health information and services needed to make appropriate oral health decisions. The current review is based on some of the extensive literature in health literacy, much of it focused on the intersection of low literacy and the understanding of basic health care information. Health literacy is a non-pharmacological method of managing and preventing diseases. There are three distinct levels in oral health literacy, i.e. functional, interactive and critical. Health literacy is important for all adults, who must be able to read articles and magazines about oral and general health prevention, interpret instructions on prescription bottles and over-the-counter medications, manage the healthcare needs of their children and ageing parents and interpret insurance and Medicare rules, regulations and benefits. There are several factors which impact on low health literacy level in the community. Poor health literacy is considered as a contributor of poor oral health status in an individual, poor heath outcome in a community and health inequalities. The dental profession is indeed changing the tide and now recognizes that several solutions can be implemented to ensure effective communication becomes a national organizational priority to improve oral healthcare.

Key words: Health knowledge, health literacy, literacy tools, oral health literacy

\section{Sudhir Hongal, Nilesh Arjun Torwane, Pankaj Goel, Byalakere}

R. Chandrashekar, Manish Jain, Eshani Saxena

Department of Public Health Dentistry, People's Dental Academy, People's University, Bhopal, M.P., India.

Address for the Correspondence:

Dr. Nilesh Arjun Torwane, Department of Public Health Dentistry, People's Dental Academy, People's University, Bhopal, M.P., India.

E-mail: nealdip@gmail.com

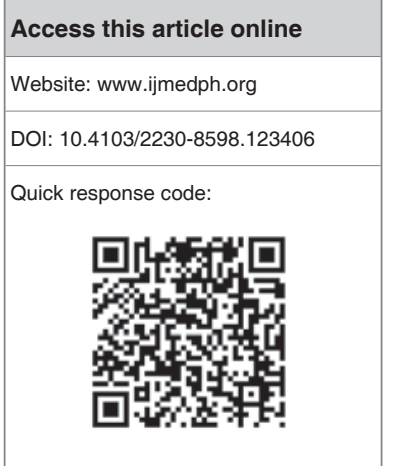

\section{INTRODUCTION}

There are many reasons why preventable diseases remain so common and why people often do not adopt practices that have been scientifically shown to be effective in maintaining health. These range from social, ${ }^{[1]}$ environmental, ${ }^{[2]}$ biological, behavioral, ${ }^{[3]}$ community, cultural, financial and political factors, ${ }^{[3,4]}$ lack of access to oral health care services, complicated oral health care systems, lack of oral health information material ${ }^{[5]}$ and low oral health literacy. ${ }^{[6]}$

Since; the modern health care system makes complex demands on the health consumers' side, this lead them to face several challenges to seek health care and its information. As a result, the health consumers with low health literacy are left unable to reap the benefits of available information.

Health literacy is increasingly described as the currency for improving the quality of health and health care. ${ }^{[7]}$ It's the basic reading and numerical skills that allow a person to function in the health care environment. There are various definitions of health literacy in literature. The widely accepted definition is "the degree to which individuals have the capacity to obtain, process and understand basic health information and services needed to make appropriate health decisions". ${ }^{\left[{ }^{7]}\right.}$ The American Medical Association (AMA) more specifically defines functional health literacy as "the ability to read and comprehend prescription bottles, appointment slips and the other essential health related materials required to successfully function as a patient". ${ }^{8]}$

The process of acquiring oral health information, appraising its concepts and applying oral health prevention and treatment plans appropriately requires new skill development called oral health literacy (OHL) ${ }^{[6]}$ Oral health literacy is an interplay between culture and society, the health system, education system, language and oral health outcomes ${ }^{[5,9]}$ indicating that it may be a new determinant of oral health and should be considered more intensively in oral health research. The significance of oral health literacy and its role in oral health promotion was highlighted in the Surgeon General's report on oral health. In January 2004, National Institute of Dental and Craniofacial Research 
(NIDCR) convened a working group on Literacy and Its Relationship with Oral Health, the group adapted the health literacy definition proposed by Healthy People 2010 to the context of oral health as "The degree to which individuals have the capacity to obtain, process and understand basic oral health information and services needed to make appropriate health decisions". ${ }^{[10]}$ Furthermore, according to the report, the literacy barrier to oral health has been largely invisible until recently because it was seldom recognized and poorly understood and many health care providers could not address the literacy needs of their patients. As a result, they presented information without ensuring that their communication was clear and successful. They also tend to use materials that were readily available but difficult to understand, this made patients reluctant to admit that they did not comprehend the information presented. Many patients also were found to be uncomfortable asking questions or requesting more information. ${ }^{[10]}$

Aware of the need to change the tide, dentistry has made improvements in terms of determining the scope of low oral health literacy and who is affected by it; understanding the financial and health-related burdens placed on care providers and patients; and defining how to achieve oral health literacy on an individual and community basis. Achieving more than a minimal level of improvement in oral health literacy has required dental professionals to change from the comfortable, individual patient-centered educational and promotional approach to the multifactorial method of individual, cultural and community factors that affect oral health literacy, risk communication and improved outcomes.

This article primarily defines on oral health literacy, emphasizes its importance and integral relationship with health literacy, impacts of low oral health literacy, different tools used to assess the literacy level in dentistry and suggests few tips for dental professionals to improve the literacy level among the general population seeking the dental care.

\section{MATERIALS AND METHODS}

The current review is based on some of the extensive literature in health literacy, much of it focused on the intersection of low literacy and the understanding of basic health care information. Articles with other documents for this review were selected by searching MEDLINE and related databases, such as Web of Science, ERIC, Psych INFO, LISA, CINAHL, Indus Medicus and BIOSIS; by consulting existing bibliographies; by using both forward and backward reference chaining techniques and by tracking recent activities in oral health literacy. References that were primarily anecdotal or that were only peripherally related to the topic were excluded.

\section{Importance and key features of health literacy}

A two-year-old was diagnosed with an inner ear infection and was prescribed an antibiotic. Her mother understood that her daughter should take the prescribed medication twice a day. After carefully studying the label on the bottle and deciding that it didn't tell how to take the medicine, she filled a teaspoon and poured the antibiotic into her daughter's painful ear. ${ }^{[1]}$ The example reflects how patients with low health literacy are vulnerable to misunderstandings and misinterpretations which may result in devastating results at times.

Health literacy is an excellent antidote to these confusions in health care. Health literacy is a non-pharmacological method of managing and preventing diseases. ${ }^{[12]}$ Basic health knowledge is needed in order to have a healthy life. Health literacy is important for all adults, who must be able to read articles and magazines about oral and general health prevention, interpret instructions on prescription bottles and over-the-counter medications, manage the healthcare needs of their children and aging parents and interpret insurance and Medicare rules, regulations, and benefits. ${ }^{[12]}$ Overwhelming developments in information technology and rapid advances in medical scientific knowledge demand that the public get an everincreasing understanding of diseases for good decision-making and for self-management of diseases. Naidu (2008) indicates health literacy as the "cornerstone of many other life skills". ${ }^{[13]}$

In 1974, the term health literacy was first used in a discussion of health education as a policy issue affecting the health system. ${ }^{[14]}$ Some key features of low health literacy include, Low health literacy will interfere with the ability to process and understand information about health; ${ }^{[0]}$ Low health literacy is associated with a range of poor health outcomes; ${ }^{[14]}$ and data from many developed countries show a relationship between low health literacy levels and improper use of available health services. ${ }^{[14]}$ The WHO commission on the social determinants of health, identified health literacy as having a central role in determining inequalities in health in both rich and poor countries. ${ }^{[4]}$ According to the American Medical Association, poor health literacy is a stronger predictor of an individual's health than age, income, employment status, educational level, or race. ${ }^{[8]}$

\section{Dimensions of oral health literacy}

According to Kickbusch, Maag, and Kris (2008) there are five important key dimensions for oral health literacy. Those are: ${ }^{[15]}$

1. Oral health care system knowledge and utilization;

2. Basic oral health knowledge;

3. Market and consumer behavior;

4. Oral health competencies at the workplace and

5. Political participation.

\section{Oral health literacy levels}

There are three distinct levels in oral health literacy, which are the functional, interactive and critical. ${ }^{[16,17]}$

1. Functional: basic skills in reading and writing necessary for effective functioning in a health context;

2. Interactive: more advanced cognitive literacy and social skills that enable active participation in health care; and

3. Critical: the ability to critically analyze and use information to participate in actions that overcome structural barriers to health." 
The oral health literacy is a distinct concept, rather than a derivative concept from literacy and numeracy skills. The oral Health literacy is considered to be obtained and processed in the following way; ${ }^{[18]}$ [Figure 1].

\section{According to the figure:}

- A person with general literacy, ability to understand health information; and ability to access health information is expected to have high level of health knowledge.

- Basic health knowledge will possibly increase the interest in receiving health information. At the same time, interest in getting health information is expected to increase the health literacy.

- Health knowledge will help an individual to participate in shared-decision making in health care. By participating in shared-decision making, the existing level of health knowledge is expected to be increased with the help of health care providers.

- Thereby, a person with high level of health literacy will have healthy behaviors and attitudes and also they will self-manage diseases and participate well in shared- decision making.

\section{Health literacy statistics worldwide}

The overall average oral health literacy level among the population appears to be low. The level of health literacy among Australian adults is comparatively higher than Canada, United States of America and New Zealand adults. ${ }^{[19]}$ [Table 1]

Results from the National Assessment of Adult Literacy (NAAL) reported that on average health literacy levels were lower among particular ethnic minorities (Black, Hispanic, American Indian/ Alaska Native, and multiracial adults), men, older adults, those in poverty, those who received publically funded insurance, those with lower levels of education and those who failed to finish high school. ${ }^{[17,20]}$ Furthermore; the report stated that most of the adults with higher levels of health literacy received their health information from the internet compared to those with lower levels, who relied primarily on "magazines and newspapers." Moreover, those with the

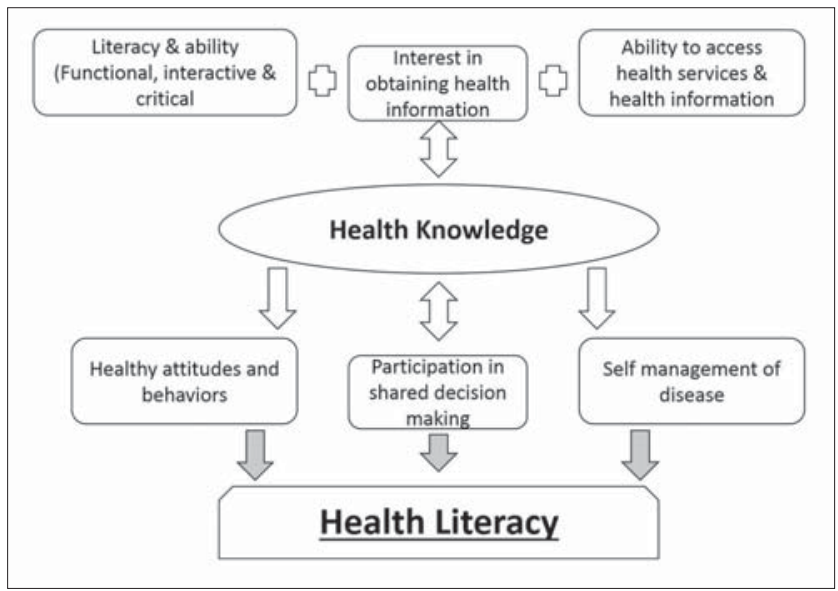

Figure 1: Flow chart that describes the process in health literacy lowest levels, were the least likely to use the internet and received the majority of their health information by radio or television rather than print media. ${ }^{[20]}$

\section{Impact and outcomes of low oral health literacy}

A committee formed by the Institution of Medicine in the U.S. to understand health literacy and its impact on health outcomes have developed a health literacy framework [Figure 2].

This framework identifies three major areas that may play important roles in shaping individuals health literacy: culture and society, the health system and the education system. Interventions should be directed towards these three areas to improve health literacy. ${ }^{[16]}$

There are several factors which impact on low health literacy level in the community. Those are difficulty in navigating the health care system; increased risk of hospitalization and emergency care use; ${ }^{[21]}$ lower use of preventive services (fluoride toothpaste, flu shots, screening for children) ${ }^{[22]}$ difficulty in understanding and completing documents and consent form; inability to read directions for prescriptions; ${ }^{[23]}$ use of more expensive services; misuse of medications; misunderstanding of self-care instructions and practice of less preventive health care. ${ }^{[24-26]}$ Other factors that can be added to this list are depression due to misunderstanding of one's disease conditions; increased use of specialty care; increased need for health care work force; and poor response in health care research and surveys. ${ }^{[27]}$

Poor health literacy is considered as a contributor of poor oral health status in an individual, poor heath outcome in a community

\section{Table 1: Health literacy statistics}

\begin{tabular}{lc}
\hline Country & $\begin{array}{c}\text { Percentage of poor health literacy } \\
\text { (Adult: 16-65 years) }\end{array}$ \\
\hline Canada & $60.0 \%$ \\
Australia & $57.0 \%$ \\
New Zealand & $56.2 \%$ \\
United States & $-28.0 \%$ (Whites) \\
of America & $-57.0 \%$ (Black) \\
(Major ethnic groups) & $-65.0 \%$ (Hispanic) \\
\hline
\end{tabular}

(Source: Health Literacy Statistics, 2010)

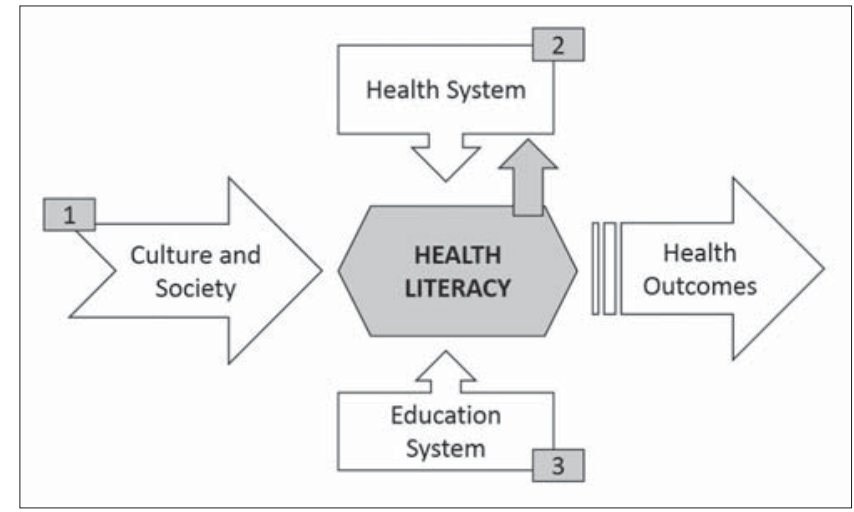

Figure 2: Health Literacy Framework 
and health inequalities. The overall major consequence is the cost as the patients with relatively low health literacy use more health care resources than those with higher literacy abilities. ${ }^{[28]}$ Health care costs due to low health literacy in the USA are estimated at \$US 73 billion and at 77.5 billion pounds in the European Union. ${ }^{[29]}$ Another study estimated the cost for an individual due to lack of health literacy as US\$143-7,798. ${ }^{[30]}$

Some of the reasons for increased health care costs due to a lack of health literacy in the community are:

- $\quad$ People with a low level of health literacy are less likely to seek treatment from primary care providers which leads into hospital admission and to specialist consultations. ${ }^{[31]}$

- Due to an inadequate awareness about diseases, patients with a low level of health literacy will seek treatment in the final stage of the diseases such as cancer and diabetes. This might increase the treatment cost due to more complicated and expensive intervention requirements at the stage of the diseases. ${ }^{[31]}$

- They are less likely to use preventive services such as vaccination and screening. ${ }^{[29]}$

- $\quad$ They are more likely to use emergency services. ${ }^{[31]}$

Health literacy can also impact oral health. Adults with inadequate oral health literacy have poorer oral health knowledge, tend to have fewer dental visits, and are more likely to report poor or fair oral health. ${ }^{[32]}$ Oral health literacy varies between racial groups; those from ethnic minorities tend to have inadequate literacy levels that may impact their oral health. ${ }^{[33,34]}$ Children of parents with low literacy have poor reported oral health ${ }^{[35,36]}$ and are less likely to have sealants on their permanent teeth. ${ }^{[37]}$ Miller and colleagues ${ }^{[35]}$ examined the association between caregiver's literacy and preschool children's oral health. This study evaluated clinical oral health status and oral health behavior of children, caregiver's oral health knowledge and children's oral health as perceived by their caregiver. There was a significant association between caregiver's oral health literacy and children's oral health as determined by both clinical examination and caregiver's perception. Oral health knowledge and behavior was not found to be affected by literacy, however; another study concluded that low levels of oral health literacy were associated with poor knowledge and behavior among low-income mothers. ${ }^{[36]}$ This variation between the two studies could be the result of the different characteristics of their study populations, especially the level of education.

\section{Tools for assessing the oral health literacy}

The first two measures of health literacy developed focus on an individual's ability to read and on word recognition. The Rapid Estimate of Adult Literacy in Medicine (REALM) test was developed by Davis et al. in 1991; this tool assesses word recognition and pronunciation skills. ${ }^{[38]}$ The second instrument, Test of Functional Health Literacy in Adults (TOFHLA), was developed in 1995 and it measures reading comprehension and numeracy skills. ${ }^{[39]}$ Other instruments use screening questions to assess a patient's ability to read and write the necessary information in a medical setting; an example of such a scale is the health literacy scale developed by Chew et al. ${ }^{[40]}$ which is a short questionnaire used to identify patients with inadequate health literacy. These instruments have been validated and are used widely in the medical literature; however, they are limited to measuring individuals" ability to read and write while health literacy itself goes beyond that. ${ }^{[41]}$

To measure oral health literacy, researchers developed modified versions of the REALM: Rapid Estimate of Adult Literacy in Dentistry (REALD). ${ }^{[42,43]}$ There are two versions of this tool (REALD-30 and REALD-99) depending on the number of words used in the instrument. Atchison et al. ${ }^{[44]}$ created a new instrument based also on REALM; this new instrument (REALM-D) combines both medical and dental terms into a single 84-item scale to screen for oral health literacy and was found to be a valid and reliable measure when tested on a diverse sample of dental clinics patients in the USA. Other instruments used in the dental literature are based on the TOFHLA; ${ }^{[45]}$ for example, the Test of Functional Health Literacy in Dentistry (TOFHLiD) assesses comprehension and numeracy skills for dental patients. These instruments have the same limitations as their original versions: they focus only on word recognition and numeracy skills. More recently, another instrument was developed by Sabbahi et al..$^{[4]}$ to determine the oral health literacy of adults: Oral Health Literacy Instrument (OHLI). In addition to comprehension and numeracy skills, OHLI also measures oral health knowledge in an attempt to capture another dimension of health literacy. With the increasing interest in health literacy in the last 25 years, it has become clear that health literacy is a multi-dimensional concept, which further complicates the development of a single scale to measure all dimensions of health literacy. Frisch et al. ${ }^{[47]}$ suggest that other domains of literacy should be incorporated into health literacy to develop an extensive scale inclusive of different dimensions such as functional, critical, attitude, awareness and procedural knowledge. To date, such an instrument does not exist but the research is ongoing.

\section{Guidelines for dental healthcare professionals to improve oral health literacy}

To enhance the likelihood of positive oral care outcomes, dentistry is developing a greater knowledge of how to interact with patients who have low oral health literacy and are "at risk." Numerous researchers in the dental profession recently have undertaken efforts to study how best to communicate with and improve oral health outcomes among low oral health literacy populations. ${ }^{[2,32,48]}$ Organized dentistry has come to acknowledge that it is incumbent on dentists and auxiliaries to understand the beliefs, values, cultural mores and traditions of their patients in order to influence how dental health care information is processed. ${ }^{[49,50]}$

A key part of clear communication and improving low oral health literacy is the use of plain language. This term refers to communications that engage and are accessible to their intended audiences. ${ }^{[51]}$ Plain language embodies clear communication and offers healthcare professionals an opportunity to make patientcentered clear communication, the accepted standard through which necessary policy and resource support can be garnered for broad and 
sustained diffusion. Using plain language facilitates accessible health communication to become the norm, rather than the exception, in medicine and dentistry. ${ }^{[51]}$

The dental profession is indeed changing the tide and now recognizes that several solutions can be implemented to ensure effective communication becomes a national organizational priority to improve oral healthcare. It is recommended that health care providers: ${ }^{[47,48,52]}$

- Recognize and respond to the changing demographics of dentistry with strong consideration and admission of qualified minority students into dental schools.

- Encourage and develop educational opportunities for increased cultural competence.

- Educate all team members within the organization to recognize and respond appropriately to patients with literacy and language needs.

- Create patient-centered environments that stress the use of clear communication in all interactions with patients, from the first encounter at the reception desk to the last words prior to the patient's departure.

- Revise all informed consent and educational materials from "professional language" to "plain language" format to foster increased and generalized understanding among all patient populations.

- Develope plans to accommodate patients with special literacy and language needs.

- Use well-trained dental interpreters for patients with low English proficiency or hearing impairments.

- Create an organizational environment of safety and quality that values patient-centered communications as an integral component of the delivery of patient-centered care.

Reduce the informational burden and more effectively communicate with dental patients and the public.

\section{CONCLUSION}

From the reviewed literature on oral health related literacy the following conclusion can be drawn:

- The process of acquiring oral health information, appraising its concepts, and applying oral health prevention and treatment plans appropriately requires new skill development called oral health literacy (OHL).

- Oral health literacy is an interplay between culture and society, the health system, education system, language and oral health outcomes indicating that it may be a new determinant of oral health and should be considered more intensively in oral health research.

- There are several factors which impact on low health literacy level in the community. Those are difficulty in navigating the health care system; increased risk of hospitalization and emergency care use; lower use of preventive services; difficulty in understanding and completing documents and consent form; inability to read directions for prescriptions; use of more expensive services; misuse of medications; misunderstanding of self-care instructions and practice of less preventive health care.
Literacy tools such as Rapid Estimate of Adult Literacy in Dentistry (REALD) i.e. REALD-30 and REALD-99; Test of Functional Health Literacy in Dentistry (TOFHLiD); and Oral Health Literacy Instrument (OHLI) can be used to assess the degree of oral health literacy.

- To enhance the likelihood of positive oral care outcomes, dentistry should develop a greater knowledge of how to interact with patients who have low oral health literacy and are at risk.

\section{REFERENCES}

1. Vanobbergen J, De Visschere L, Daems M, Ceuppens A, Van Emelen J. Socio-demographic determinants for oral health risk profiles. Int J Dent 2010;2010:938936.

2. Newton JT, Bower EJ. The social determinants of oral health: New approaches to conceptualizing and researching complex causal networks. Community Dent Oral Epidemiol 2005;33:25-34.

3. Patrick DL, Lee RS, Nucci M, Grembowski D, Jolles CZ, Milgrom P. Reducing oral health disparities: A focus on social and cultural determinants. BMC Oral Health 2006;6:S4.

4. Petersen PE. The World Oral Health Report 2003: Continuous improvement of oral health in the 21st century-the approach of the WHO Global Oral Health Programme. Community Dent Oral Epidemiol 2003;31:3-24.

5. National Institute of Dental and Craniofacial Research, National Institute of Health, U.S. Public Health Service, Department of Health and Human Services. The invisible barrier: Literacy and its relationship with oral health. A report of a workgroup sponsored by the national institute of dental and craniofacial research, national institutes of health. J Public Health Dent 2005;65:174-82.

6. Horowitz AM, Kleinman DV. Oral health literacy: A pathway to reducing oral health disparities in Maryland. J Public Health Dent 2012;72:S26-30.

7. Davis RM. Healthy People 2010": National health objectives for the United States. BMJ 1998;317:1513-7.

8. Safeer RS, Keenan J. Health Literacy: The Gap between Physicians and Patients. Am Fam Physician 2005;72:463-8.

9. Horowitz AM, Kleinman DV. Oral health literacy: The new imperative to better oral health. Dent Clin North Am 2008;52:333-44.

10. National Institute of Dental and Craniofacial Research, National Institute of Health, U.S. Public Health Service, Department of Health and Human Services. The invisible barrier: Literacy and its relationship with oral health. A report of a workgroup sponsored by the National Institute of Dental and Craniofacial Research, National Institute of Health, U.S. Public Health Service, Department of Health and Human Services. J Public Health Dent 2005;65:174-82.

11. Lynn BN. Panze, Allison M. Health Literacy: A Prescription to end Confusion, Committee on health literacy. 2004. Available from: http:// www.books.google.co.nz/books?id=rAeq4gzavQUCandlpg=PP1andpg= PP1\#v=onepag and qandf=false. [Last accessed on 2013 Feb 10].

12. American Dental Association. Communication between health care providers and patients: Addressing the challenges of limited oral health literacy. A-Z topics: Science in the News; 2007. [Last accessed on 2013 Feb 10].

13. Naidu A. Health literacy. Whitireia Nurs J 2008;5:39-46.

14. Nutbeam D. The evolving concept of health literacy. Soc Sci Med 2008;67:2072-8.

15. Kickbusch I, Maag D, Kris H. Health Literacy. International Encyclopedia of Public Health. Oxford: Academic Press; 2008. p. 204-11.

16. Nutbeam D. Health Literacy as a Public Health Goal: A Challenge for Contemporary Health Education and Communication Strategies into the 21st Century. Health Promot Int 2000;15:259-67.

17. Coultzer A, Parsons S, Askham J. Where are the patients in decision making about their own care?: WHO Regional office for Europe. 2008; Available from: http://www.euro.who.int/_data/assets/pdf_ file/0007/73285/E93419.pdf. [Last accessed on 2013 Feb 13].

18. Peter S. Essentials of Preventive and Community dentistry: $3^{\text {rd }}$ Edition New Delhi Arya Publishing House; 2001. 
19. Health literacy New Zealand. Health literacy statistics. 2010. Available from: http://www.healthliteracy.org.nz/about-health-literacy/health-literacystatistics/._[Last accessed on 2013 Feb 10].

20. What is literacy? National Assessment of Adult Literacy. Available from: http://www.nces.ed.gov/naal/. [Last accessed on 2013 Feb 13].

21. Howard DH, Gazmaraian J, Parker R. The Impact of Low Health Literacy on the Medical Costs of Medicare Managed Care Enrollees. Am J Med 2005;118:371-7.

22. Bennett IM, Chen J, Soroui JS, White S. The Contribution of Health Literacy to Disparities in Self-Rated Health Status and Preventive Health Behavior in Older Adults. Ann Fam Med 2009;7:204-11.

23. Kripalani S, Henderson LE, Chiu EY, Robertson R, Kolm P, Jacobson TA. Predictors of Medication Self-Management Skill in a Low-Literacy Population. J Gen Intern Med 2006;21:852-6.

24. Quandt SA, Chen H, Bell RA, Anderson AM, Savoca MR, Kohrman T, et al. Disparities in oral health status between older adults in a multiethnic rural community: The rural nutrition and oral health study. J Am Geriatr Soc 2009;57:1369-75.

25. Kutner ME, Greenberg D, Jin Y, Christine Paulsen. The Health Literacy of America's Adults: Results from the 2003 National Assessment of Adult Literacy. Washington, DC: National Center for Education Statistics, US Department of Education; 2006. Available from: http://www.nces.ed.gov/ pubs2006/2006483_1.pdf. [Last accessed on 2013 Feb 13].

26. Eckman MH, Wise R, Leonard AC, Dixon E, Burrows C, Khan F, et al. Impact of health literacy on outcomes and effectiveness of an educational intervention in patients with chronic diseases. Patient Educ Couns 2012;87:143-51.

27. Hussey LC. Minimizing effects of low literacy on medication knowledge and compliance among the elderly. Clin Nurs Res 1994;3:132-45.

28. Eagle L, Reid J, Hawkins J, Styles E. Breaking through the invisible barrier of low functional health literacy: Implications for health communication. Stud Commun Sci 2005;5:29-56.

29. Kemp G, Eagle L. Shared meanings or missed opportunities? The implications of functional health literacy for social marketing interventions. Int Rev Public Nonprofit Mark 2008;5:117-28.

30. Eichler K, Wieser S, Brügger U. The costs of limited health literacy: A systematic review. Int J Public Health 2009;54:313-24.

31. Ministry of Health. Korero Marama: Health literacy and Maori. (978-0478 31985-9). 2010. Available from: http://www.maorihealth.govt.nz/ moh.nsf/pagesmh/9932/\$File/korero-marama.pdf. [Last accessed on 2013 Feb 14].

32. Jones M, Lee JY, Rozier RG. Oral health literacy among adult patients seeking dental care. J Am Dent Assoc 2007;138:1199-208.

33. Lee JY, Divaris K, Baker AD, Rozier RG, Lee SY, Vann WF Jr. Oral health literacy levels among A Low-Income WIC population. J Public Health Dent 2011;71:152-60.

34. Parker EJ, Jamieson LM. Association between indigenous Australian oral health literacy and self-reported oral health outcomes. BMC Oral Health 2010;10:3.

35. Miller E, Lee JY, DE Walt DA, Vann WF Jr. Impact of caregiver literacy on children's oral health outcomes. Pediatrics 2010;126:107-14.

36. Vann WF Jr, Lee JY, Baker D, Divaris K. Oral Health literacy among female caregivers: Impact on oral health outcomes in early childhood. J Dent Res 2010;89:1395-400.
37. Mejia GC, Weintraub JA, Cheng NF, Grossman W, Han PZ, Phipps KR et al. Language and literacy relate to lack of children's dental sealant use. Community Dent Oral Epidemiol 2011;39:318-24.

38. Davis TC, Crouch MA, Long SW, Jackson RH, Bates P, George RB Rapid assessment of literacy levels of adult primary care patients. Fam Med 1991;23:433-5

39. Parker RM, Baker DW, Williams MV, Nurss JR. The test of functional health literacy in adults: A new instrument for measuring patients literacy skills. J Gen Intern Med 1995;10:537-41.

40. Chew LD, Bradley KA, Boyko EJ. Brief Questions to Identify Patients with Inadequate Health Literacy. Fam Med 2004;36:588-94.

41. U.S. Institute of Medicine. Measures of health literacy: Workshop summary. Washington DC: The National Academies Press; 2009.

42. Lee JY, Rozier RG, Lee SY, Bender D, Ruiz RE. Development of a word recognition instrument to test health literacy in dentistry: The REALD-30-a brief communication. J Public Health Dent 2007;67:94-8.

43. Richman JA, Lee JY, Rozier RG, Gong DA, Pahel BT, Vann WF Jr. Evaluation of a word recognition instrument to test health literacy in dentistry: The REALD-99. J Public Health Dent 2007;67:99-104.

44. Atchison KA, Gironda MW, Messadi D, Der-Martirosian C. Screening for oral Health Literacy in an Urban dental clinic. J Public Health Dent 2010;70:269-75

45. Gong DA, Lee JY, Rozier G, Pahel BT, Vann WF. Development and testing of the test of functional health literacy in dentistry (TOFHLiD). J Public Health Dent 2007;67:105-12.

46. Sabbahi DA, Lawrence HP, Limeback H, Rootman I. Development and evaluation of an oral health literacy instrument for adults. community Dent Oral Epidemiol 2009;37:451-62.

47. Frisch AL, Camerini L, Diviani N, Schulz PJ. Defining and measuring health literacy: How Can we profit from other literacy domains? Health Promot Int 2012;27:117-26.

48. Garcia RI, Cadoret CA, Henshaw M. Multicultural issues in oral health. Dent Clin North Am 2008;52:319-32.

49. What Did the Doctor Say? Improving Health Literacy to Protect Patient Safety. Oakbrook Terrace, IL: Joint Commission on Accreditation of Healthcare Organizations; 2007. Available from: http://www. jointcommission.org/assets/1/18/improving_health_literacy.pdf. [Last accessed on 2013 Feb 14].

50. Kutner ME, Greenberg D, Jin Y, Christine Paulsen. The Health Literacy of America's Adults: Results from the 2003 National Assessment of Adult Literacy. Washington, DC: National Center for Education Statistics, US Department of Education; 2006. Available from: http:// www.wapatientsafety.org/.../GNielsen-Health-Literacy-Resources.doc. [Last accessed on 2013 Feb 14].

51. Stableford S, Mettger W. Plain language: A strategic response to the health literacy challenge. J Public Health Policy 2007;28:71-93.

52. Roter DL, Erby L, Larson S, Ellington L. Oral literacy demand of prenatal genetic counseling dialogue: Predictors of learning. Patient Educ Couns 2009;75:392-7.

How to cite this article: Hongal S, Torwane NA, Goel P Chandrashekar BR, Jain M, Saxena E. Assessing the oral health literacy: A review. Int J Med Public Health 2013;3:219-24.

Source of Support: Nil, Conflict of Interest: None declared. 